\title{
Research of Loss Reduction Scheme for Regional Distribution Grids Based On $\mathrm{G}_{1}$-GRA
}

\author{
W. Zhang \\ Taiyuan University of Technology \\ Taiyuan, China
}

\author{
Y.M. Liu, W.Q. Ma \\ Yangquan Power Supply Company \\ Yangquan, China
}

\begin{abstract}
- this paper proposed a comprehensive loss reduction evaluation method for regional distribution grids based on $\mathbf{G}_{1}$ method and grey relational analysis (GRA). The method is good at avoiding the prominent disadvantages of analytic hierarchy process (AHP) by determining the weights of evaluation indices. Otherwise, the method of grey relational analysis was used for dimensionless processing. Therefore, the authors put forward an implementation scheme about the preferred area for loss reducing and the optimal index, which is proved to be practical, significant, and applicable.
\end{abstract}

Keywords-distribution network; g1 method; grey relational analysis; combination evaluation

\section{INTRODUCTION}

Line loss rate is the main economic and technical index of power network for planning, operating, and managing. Therefore, according to the need of the mechanism of power market operation, it is significant to reduce the line loss rate to a reasonable level. So the operation status of economic power grid as well as the economic benefits of power enterprises can be improved.

Among all the segments of power system, the distribution network is of significant importance for its complex network structure, serious line loss and poor reliability. Based on the above consideration, the distribution network has a large space in terms of efficiency. In order to improve the level of energy efficiency of the distribution network, it is necessary to expand the related theory. Therefore, energy efficiency index system needs to be established to evaluate the efficiency level of distribution network comprehensively. On this account, it is significant to obtain the actual conditions of distribution network and diagnose the weak line in energy efficiency, thus providing direction and suggestions for enhancing the efficiency level of distribution network.

Many domestic and foreign literature studies have involved the assessment method aiming at the reduction of distribution network loss. The model in [1] put forward a comprehensive renovation investment plan for regional distribution network based on grey connectedness weighting, which is about the combination of a variety of energy saving measures. Analytic hierarchy process is adopted in [2] to determine the weight of individual index. Based on the research about energy-saving index of distribution network, a energy efficiency index system of distribution network is established. The correlation between network loss factors and line loss rate is analyzed in [3] via the method of AHP-gray relational analysis. moreover, $\operatorname{GM}(1, \mathrm{~N})$ model has been developed through strongly correlated loss factors, for the purpose of predicting ideal line loss rate and calculating respective and comprehensive loss reduction potential. In the process of determining index weight by AHP method, a matrix needs to be constructed. And then conduct the consistency check. However, the matrix constructed is often hard to meet the requirement of consistency. So the judgment matrix usually needs to modify. The G1-GRA method is adopted in [4] to evaluate the comprehensive performance of coal-fired power plant. And the scheme is of practical significance in the comprehensive evaluation of distribution network.

Comprehensive evaluation method of loss reduction scheme concentrates on two aspects. On the one hand, the index consistent dimensionless method needs to be too proposed. On the other hand, the index weight needs to determine. Furthermore, the index characteristics of distribution network and the difference between the quantitative indicators and qualitative indicators are not considered in classical mathematics method of indicators dimensionless solutions. Subordinating degree function is attached to the fuzzy mathematics method. And it is often difficult to determine suitable function for the process of selecting the subordinating degree function is optional. Besides, in order to find out the subordinating degree function of each index, the index must be substituted into the corresponding subordinating degree function, which adding unnecessary errors. Grey relational analysis made improvement on the above mentioned method. On the process of partial treatment for single index data, the overall scheme is considered, which reduced the impact of incomplete information or asymmetry in the very great degree. In addition the method of determining the weight generally includes the expert evaluation method, AHP method, G1 method, principal component analysis method and so on.

\section{COnTEnT And StePs of G1 Method}

G1 method is a subjective weighting method, which is presented by professor Y.J.Guo of Northeastern University. This method to determine index weight makes improvements based on the analytic hierarchy process and avoids the shortcoming of AHP method effectively. In the process of determining index weight, there is no need to construct judgment matrix as well as check the consistency. Compared to the analytic hierarchy process, the computation of G1 method has significantly reduced [5-7]. Specific content is as follows: 


\section{A. Determination of Order Relationship}

Definition: if the important degree of evaluation index $\mathrm{X}_{\mathrm{i}}$, relative to a certain evaluation criteria (or target), is greater than (or less than) $X_{j}$, denoted by $X_{i}>X_{j}$.

Definition: if the indices of $\mathrm{X}_{1}, \mathrm{X}_{2} \ldots \mathrm{X}_{\mathrm{m}}$, relative to a certain evaluation criteria (or target) has the relation $\mathrm{X}_{\mathrm{i}}>\mathrm{X}_{\mathrm{j}}>\ldots>\mathrm{X}_{\mathrm{k}}$, where $\mathrm{i}, \mathrm{j} \ldots \mathrm{k}=1,2 \ldots \mathrm{M}$, then the order relation is determined according to the token ">".

\section{B. The Relative Importance of the Ratio Between $x_{k}-1$ and $x_{k}$}

According to steps as follows to build the order relation for the evaluation index set $\left\{\mathrm{x}_{1}, \mathrm{x} 2, \ldots, \mathrm{x}_{\mathrm{m}}\right\}$.

1) Find out the most important evaluation index in the index $\operatorname{set}\left\{\mathrm{x}_{1}, \mathrm{x}_{2}, \ldots, \mathrm{x}_{\mathrm{m}}\right\}$, denoted by $\mathrm{x}_{1}{ }^{*}$;

2) Find out the most important evaluation index among the rest of the $\mathrm{m}-1$ indicators, denoted by $\mathrm{x}_{2}{ }^{*}$; thus determining the only order relation $\mathrm{x}_{1}{ }^{*}>\mathrm{x}_{2}{ }^{*}>\ldots>\mathrm{x}_{\mathrm{m}}{ }^{*}$, where $\mathrm{x}_{\mathrm{i}}{ }^{*}$ means the $\mathrm{i}$ 'th evaluation index according to the order relation of " $>$ " sorted.

3) Express the relatively important degree between the indices with the ratio between adjacent index important degrees of $x_{k-1}$ and $x_{k}$, denoted by $r_{k}$. Namely, $r_{k}=\omega_{k-1}{ }^{*} / \omega_{k}{ }^{*}$. The value of $r_{k}$ is shown in Table 1 .

\section{TABLE I. 2013 STATIC DATA Of EXPEDITION FACTORS}

\begin{tabular}{|c|c|}
\hline $\mathbf{r}_{\mathbf{k}}$ & The degree of importance $\left(\right.$ compare $\mathrm{x}_{\mathbf{k}-1}$ with $\mathrm{x}_{\mathrm{k}}$ ) \\
\hline $\mathbf{1 . 0}$ & Equal importance \\
\hline $\mathbf{1 . 1}$ & Intermediate level \\
\hline $\mathbf{1 . 2}$ & Moderate importance \\
\hline $\mathbf{1 . 3}$ & Intermediate level \\
\hline $\mathbf{1 . 4}$ & Strong importance \\
\hline $\mathbf{1 . 5}$ & Intermediate level \\
\hline $\mathbf{1 . 6}$ & Very strong \\
\hline $\mathbf{1 . 7}$ & Intermediate level \\
\hline $\mathbf{1 . 8}$ & Extreme importance \\
\hline
\end{tabular}

4) Calculate the weight coefficient. If the rational assignment of $r_{k}$ is presented to meet the inequality: $r_{k-1}>1 / r_{k}$, then, $\omega_{\mathrm{m}}{ }^{*}$ can be expressed by:

$$
\begin{gathered}
\omega_{m}^{*}=\left[1+\sum_{k=2}^{m} \prod_{i=k}^{m} r_{i}\right]^{-1} \\
\omega_{k-1}^{*}=r_{k} \omega_{k}^{*}
\end{gathered}
$$

$\mathrm{k}=\mathrm{m}, \mathrm{m}-1, \mathrm{~m}-2, \cdots 3,2$. where, $\omega_{\mathrm{k}}{ }^{*}$ is the weight of the $\mathrm{k}$ 'th index.

\section{CONTENT AND StEPS OF GREy RELATIONAL ANALYSIS}

Grey relational analysis (GRA) is a kind of multiple factors analysis method. Identify the superiority of proposed scheme through calculating the degree of association between the proposed scheme and ideal scheme[8,9]. The higher the correlation, the closer for the proposed scheme to the ideal one. Moreover, the comprehensive performance is superior, and vice versa.
The solving steps of grey relational analysis are as follows:

1) According to the purpose of evaluation to determine evaluation index system and collect evaluation data. The formation of the following matrix based on the $n$ datum sequence:

$$
\left(X_{1}, X_{2}, \ldots X_{n}\right)=\left(\begin{array}{cccc}
x_{1}(1) & x_{2}(1) & \cdots & x_{n}(1) \\
x_{1}(2) & x_{2}(2) & \cdots & x_{n}(2) \\
\vdots & \vdots & \ddots & \vdots \\
x_{1}(\mathrm{~m}) & x_{2}(\mathrm{~m}) & \cdots & x_{n}(\mathrm{~m})
\end{array}\right)
$$

\section{2) Determine the reference data columns}

Reference data series is an ideal standard of comparison. The optimal value (or worst) of each index can be used to constitute the reference data column. It is also allowed to choose other reference value according to the evaluation purpose. Denoted by:

$$
X_{0}=\left(x_{0}(1), x_{0}(2), \cdots, x_{0}(m)\right)
$$

3) Method of initial value is used to quantified the criterions. Thereinto, the initial value equation of the index data, which has positive correlation relative to the reference factor $\mathrm{X} 0$ is:

$$
x_{j}^{\prime}(k)=x_{j}(k) / x_{1}(k)
$$

For the negative correlation factors, using the convert method. Convert them into positive correlation factor at first. Then conduct the initial value transformation. Calculation equation is:

$$
\begin{gathered}
x_{j}^{\prime}(k)=\left(1 / x_{j}(\mathrm{k})\right) /\left(1 / x_{1}(\mathrm{k})\right)=x_{1}(\mathrm{k}) / x_{j}(\mathrm{k}) \\
\left(X_{0}^{\prime}, X_{1}^{\prime}, \ldots X_{n}^{\prime}\right)=\left(\begin{array}{cccc}
x_{0}^{\prime}(1) & x_{1}^{\prime}(1) & \cdots & x_{n}^{\prime}(1) \\
x_{0}^{\prime}(2) & x_{1}^{\prime}(2) & \cdots & x_{n}^{\prime}(2) \\
\vdots & \vdots & \ddots & \vdots \\
x_{0}^{\prime}(\mathrm{m}) & x_{1}^{\prime}(\mathrm{m}) & \cdots & x_{n}^{\prime}(\mathrm{m})
\end{array}\right)
\end{gathered}
$$

4) Figure out the absolute difference between each appraisal object index sequence (the comparative sequence) and the reference sequence corresponding element. Get the difference sequence and find out the maximum as well as minimum value.

5) Determine the resolution coefficient $\rho$. resolution coefficientpcan be any value between zero to one. Its value will bring influence on determining the correlation value. Here's limitation of the coefficient values range: $0<\rho<1$.

$$
\begin{aligned}
& \text { If } \Delta_{\max }>3 \Delta_{v} \text {, then } \varepsilon \leq \rho \leq 1.5 \varepsilon ; \\
& \text { If } \Delta_{\max } \leq 3 \Delta_{v} \text {, then } 1.5 \varepsilon \leq \rho \leq 2 \varepsilon ;
\end{aligned}
$$

Where $\varepsilon=\Delta_{\mathrm{v}} / \Delta_{\max } . \Delta_{\mathrm{v}}$ is the mean value of the Absolute Difference. 


$$
\begin{aligned}
& \Delta_{v}=\frac{1}{m n} \sum_{j=1}^{n}\left[\sum_{k=1}^{m}\left|x_{0}(\mathrm{k})-x_{j}(\mathrm{k})\right|\right] \\
& \Delta_{\max }=\max _{1 \leq k \leq m}\left[\max _{1 \leq j \leq n}\left|x_{0}(\mathrm{k})-x_{j}(\mathrm{k})\right|\right]
\end{aligned}
$$

6) Calculate the correlation coefficient. Each reference sequence and comparative sequence are calculated separately and figure out the corresponding element of correlation coefficient via Eq.8, Eq.9.

$$
\xi_{j}(\mathrm{k})=\frac{\Delta(\mathrm{min})+\rho \times \Delta(\mathrm{max})}{\Delta_{j}(\mathrm{k})+\rho \times \Delta(\max )}
$$

The specific expression is:

$$
\xi_{j}(\mathrm{k})=\frac{\min _{j} \min _{k}\left|x_{o}(\mathrm{k})-x_{j}(\mathrm{k})\right|+\rho \times \max _{j} \max _{k}\left|x_{o}(\mathrm{k})-x_{j}(\mathrm{k})\right|}{\left|x_{o}(\mathrm{k})-x_{j}(\mathrm{k})\right|+\rho \times \max _{j} \max _{k}\left|x_{o}(\mathrm{k})-x_{j}(\mathrm{k})\right|}
$$

7) Calculate the correlation degree. the correlation degree between comparative sequence and reference sequence is reflected by $\mathrm{M}$ correlation coefficients. The equation is:

$$
r_{j}=\frac{1}{n} \sum_{k=1}^{m} \xi_{j}(\mathrm{k}), j=1,2, \cdots \mathrm{n}
$$

Determine the weighted arithmetic average according to the G1 method and get the correlation between them.

$$
r_{j}=\sum_{k=1}^{m} \xi_{j}(\mathrm{k}) \omega_{j}, \mathrm{j}=1,2, \cdots, n
$$

\section{EMPIRICAL STUDY}

In order to realize the optimization evaluation of line loss scheme, six factors are selected to be investigated, namely, feeder branch length, average load rate of distribution transformer, average load rate of feeder, insulation rate of feeder, cable rate of feeder and ring rate of feeder, denoted by $\mathrm{X}_{1}, \mathrm{X}_{2}, \mathrm{X}_{3}, \mathrm{X}_{4}, \mathrm{X}_{5}, \mathrm{X}_{6}$ respectively.

\section{The Loss Reduction Region Optimization}

Table 2 shows the static result of four regions in a given area in 2013.

TABLE II. 2013 DATA STATICS OF EXPEDITION FACTORS.

\begin{tabular}{|c|c|c|c|c|c|c|}
\hline region & $\mathbf{X 1} \mathbf{( k m )}$ & $\mathbf{X 2 ( \% )}$ & $\mathbf{X 3 ( \% )}$ & $\mathbf{X 4 ( \% )}$ & $\mathbf{X 5 ( \% )}$ & $\mathbf{X 6 ( \% )}$ \\
\hline A & 9.6 & 62.7 & 59.6 & 82.7 & 81.3 & 67.6 \\
\hline B & 11.7 & 60.9 & 62.5 & 84.1 & 80.2 & 86.2 \\
\hline C & 10.5 & 63.4 & 64.9 & 85.7 & 81.7 & 83.4 \\
\hline D & 10.3 & 61.2 & 62.6 & 86.2 & 82.6 & 57.3 \\
\hline
\end{tabular}

According to expert evaluation, index importance ranks as follows:
$\mathrm{X}_{2}>\mathrm{X}_{3}>\mathrm{X}_{1}>\mathrm{X}_{5}>\mathrm{X}_{4}>\mathrm{X}_{6}$

Comparison results of the importance of adjacent indices are listed as follows:

TABLE III. ADJACENT INDEX COMPARISON RESULTS.

\begin{tabular}{|c|c|c|c|c|c|}
\hline No. & 2 & 3 & 4 & 5 & 6 \\
\hline $\mathbf{r}_{\mathbf{k}}$ & 1.1 & 1.2 & 1.4 & 1.2 & 1.4 \\
\hline
\end{tabular}

Use the $\mathrm{G}_{1}$ method to determine the index weight coefficients:

$r_{2} r_{3} r_{4} r_{5} r_{6}=3.105 ; \quad r_{3} r_{4} r_{5} r_{6}=2.822 ; \quad r_{4} r_{5} r_{6}=2.352 ; \quad r_{5} r_{6}=1.680 ;$ $\mathrm{r}_{6}=1.200$.

TABLE IV. THE WEIGHT VALUES OF G1 METHOD.

\begin{tabular}{|c|c|c|c|c|c|c|}
\hline index & $\mathbf{X}_{\mathbf{2}}$ & $\mathbf{X}_{\mathbf{3}}$ & $\mathbf{X}_{\mathbf{1}}$ & $\mathbf{X}_{\mathbf{5}}$ & $\mathbf{X}_{\mathbf{4}}$ & $\mathbf{X}_{\mathbf{6}}$ \\
\hline weight & 0.219 & 0.199 & 0.166 & 0.118 & 0.099 & 0.082 \\
\hline
\end{tabular}

According to grey correlation analysis, feeder branch length and average load rate of feeder are reverse indices, the rest are positive indices. So the selected reference sequence is:

TABLE V. THE REFERENCE SEQUENCE VALUE.

\begin{tabular}{|c|c|c|c|c|c|c|}
\hline region & $\begin{array}{c}\mathbf{X}_{\mathbf{1}} \\
(\mathbf{k m})\end{array}$ & $\mathbf{X}_{\mathbf{2}}(\mathbf{\%})$ & $\mathbf{X}_{\mathbf{3}}(\mathbf{\%})$ & $\mathbf{X}_{\mathbf{4}}(\mathbf{\%})$ & $\mathbf{X}_{\mathbf{5}} \mathbf{( \% )}$ & $\mathbf{X}_{\mathbf{6}} \mathbf{( \% )}$ \\
\hline Reference sequence & 9.6 & 63.4 & 60.3 & 86.2 & 82.6 & 86.2 \\
\hline
\end{tabular}

Results after the initial treatment are as follows:

TABLE VI. INITIAL RESULTS.

\begin{tabular}{|c|c|c|c|c|c|c|}
\hline region & $\mathbf{X}_{\mathbf{1}}$ & $\mathbf{X}_{\mathbf{2}}$ & $\mathbf{X}_{\mathbf{3}}$ & $\mathbf{X}_{\mathbf{4}}$ & $\mathbf{X}_{\mathbf{5}}$ & $\mathbf{X}_{\mathbf{6}}$ \\
\hline $\mathbf{A}$ & 1.000 & 0.989 & 0.988 & 0.959 & 0.984 & 0.784 \\
\hline $\mathbf{B}$ & 1.219 & 0.961 & 1.036 & 0.976 & 0.971 & 1.000 \\
\hline $\mathbf{C}$ & 1.094 & 1.000 & 1.076 & 0.994 & 0.989 & 0.968 \\
\hline $\mathbf{D}$ & 1.073 & 0.965 & 1.038 & 1.000 & 1.000 & 0.665 \\
\hline Reference sequence & 1.000 & 1.000 & 1.000 & 1.000 & 1.000 & 1.000 \\
\hline
\end{tabular}

Denote $\mathrm{A}^{*}, \mathrm{~B}^{*}, \mathrm{C}^{*}, \mathrm{D}^{*}$ as the absolute difference between the reference sequence and comparative sequence.

TABLE VII. ABSOLUTE DIFFERENCE.

\begin{tabular}{|l|l|l|l|l|l|l|}
\hline $\mathbf{A}^{*}$ & 0.000 & 0.011 & 0.012 & 0.041 & 0.016 & 0.216 \\
\hline $\mathbf{B}^{*}$ & 0.219 & 0.039 & 0.036 & 0.024 & 0.029 & 0.000 \\
\hline $\mathbf{C}^{*}$ & 0.094 & 0.000 & 0.076 & 0.006 & 0.011 & 0.032 \\
\hline $\mathbf{D}^{*}$ & 0.073 & 0.035 & 0.038 & 0.000 & 0.000 & 0.335 \\
\hline
\end{tabular}

Then, $\quad \Delta(\max )=0.335, \quad \Delta(\min )=0, \quad \Delta \mathrm{v}=0.056, \quad \varepsilon=\Delta \mathrm{v}$ $/ \Delta \max =0.167$. It is known from Eq.8, Eq.9, if $\Delta \max >3 \Delta v$, then $0.167 \leq \rho \leq 0.2505$, take the median, then $\rho=0.21$.

Grey relational coefficient list:

TABLE VIII. GREY RELATIONAL COEFFICIENT

\begin{tabular}{|l|l|l|l|l|l|l|}
\hline$\xi_{\mathbf{1}}(\mathbf{k})$ & 1.000 & 0.864 & 0.858 & 0.634 & 0.817 & 0.246 \\
\hline$\xi_{2}(\mathbf{k})$ & 0.243 & 0.641 & 0.658 & 0.743 & 0.708 & 1.000 \\
\hline$\xi_{3}(\mathbf{k})$ & 0.429 & 1.000 & 0.480 & 0.924 & 0.866 & 0.684 \\
\hline$\xi_{4}(\mathbf{k})$ & 0.491 & 0.670 & 0.648 & 1.000 & 1.000 & 0.173 \\
\hline
\end{tabular}

Obtain the grey correlation degree via the G1-GRA method. 
TABLE IX. GREY COEFFICIENT DEGREE OF EACH REGION.

\begin{tabular}{|c|c|c|c|c|}
\hline region & A & B & C & D \\
\hline Grey coefficient degree & 0.705 & 0.551 & 0.635 & 0.588 \\
\hline
\end{tabular}

It is can been seen that the network loss reduction condition of region $\mathrm{A}$ is the best of all and region $\mathrm{B}$ is the worst. So region B if preferred to implement the loss reduction scheme.

\section{The Loss Reduction Index Optimization}

Table 10 shows the static results of corresponding indices of region B in 2009-2013.

TABLE X. STATISTIC DATA OF REGION B IN 2009-2013.

\begin{tabular}{|c|c|c|c|c|c|c|c|}
\hline year & $\mathbf{X}_{\mathbf{0}}(\mathbf{\% )}$ & $\mathbf{X}_{\mathbf{1}} \mathbf{( k m )}$ & $\mathbf{X}_{\mathbf{2}}(\mathbf{\%})$ & $\mathbf{X}_{\mathbf{3}}(\mathbf{\%})$ & $\mathbf{X}_{\mathbf{4}}(\mathbf{\%})$ & $\mathbf{X}_{\mathbf{5}}(\mathbf{\%})$ & $\mathbf{X}_{\mathbf{6}}(\mathbf{\% )}$ \\
\hline 2009 & 6.48 & 12.3 & 59.7 & 65.7 & 75.3 & 71.7 & 59.4 \\
\hline 2010 & 6.35 & 12.1 & 61.3 & 64.3 & 77.2 & 74.6 & 65.7 \\
\hline 2011 & 6.17 & 11.9 & 61.3 & 63.1 & 81.3 & 75.3 & 81.2 \\
\hline 2012 & 6.02 & 11.9 & 60.5 & 63.1 & 82.3 & 79.2 & 84.6 \\
\hline 2013 & 5.99 & 11.7 & 60.9 & 62.5 & 84.1 & 80.2 & 86.2 \\
\hline
\end{tabular}

Determine the weight of each index via G1 method. The results are shown in Table 4 . The grey correlation degree calculation results are as follows:

$$
\left(X_{0}, X_{1}, X_{2}, X_{3}, X_{4}, X_{5}, X_{6}\right)=\left(\begin{array}{lllllll}
6.48 & 12.3 & 59.7 & 65.7 & 75.3 & 71.7 & 59.4 \\
6.35 & 12.1 & 61.3 & 64.3 & 77.2 & 74.6 & 65.7 \\
6.17 & 11.9 & 61.3 & 63.1 & 81.3 & 75.3 & 81.2 \\
6.02 & 11.9 & 60.5 & 63.1 & 82.3 & 79.2 & 84.6 \\
5.99 & 11.7 & 60.9 & 62.5 & 84.1 & 80.2 & 86.2
\end{array}\right)
$$

Through initialization operators, the original data can be transformed into dimensionless data. The shorter the length of feeder $X_{1}$ and the smaller the average load rate of feeder $X_{3}$, the smaller the rate of the comprehensive line loss. So $X_{1}$ and $\mathrm{X}_{3}$ are positive correlation factors, compared with $\mathrm{X}_{0}$. The rest of the indices are negative correlation factors. Therefore, after initialization and the reciprocal treatment, the results are shown as follows:

TABLE XI. INITIALIZATION RESULTS.

\begin{tabular}{|c|c|c|c|c|c|c|c|}
\hline year & $\mathbf{X}_{\mathbf{0}}$ & $\mathbf{X}_{\mathbf{1}}$ & $\mathbf{X}_{\mathbf{2}}$ & $\mathbf{X}_{\mathbf{3}}$ & $\mathbf{X}_{\mathbf{4}}$ & $\mathbf{X}_{\mathbf{5}}$ & $\mathbf{X}_{\mathbf{6}}$ \\
\hline 2010 & 1.000 & 1.000 & 1.000 & 1.000 & 1.000 & 1.000 & 1.000 \\
\hline 2011 & 0.980 & 0.984 & 0.974 & 0.979 & 0.975 & 0.961 & 0.904 \\
\hline 2012 & 0.952 & 0.967 & 0.974 & 0.960 & 0.926 & 0.952 & 0.732 \\
\hline 2013 & 0.929 & 0.967 & 0.987 & 0.960 & 0.915 & 0.905 & 0.702 \\
\hline 2014 & 0.924 & 0.951 & 0.980 & 0.951 & 0.895 & 0.894 & 0.689 \\
\hline
\end{tabular}

Compute the absolute difference value of the comparative sequence and the reference sequence. And then list the difference sequence below.
TABLE XII. DIFFERENCE SEQUENCE.

\begin{tabular}{|c|c|c|c|c|c|}
\hline $\mathrm{X}_{1}^{*}$ & $\mathrm{X}_{2}^{*}$ & $\mathrm{X}_{3}^{*}$ & $\mathrm{X}_{4}^{*}$ & $\mathrm{X}_{5}^{*}$ & $\mathrm{X}_{6}^{*}$ \\
\hline 0.000 & 0.000 & 0.000 & 0.000 & 0.000 & 0.000 \\
\hline 0.004 & 0.006 & 0.001 & 0.005 & 0.019 & 0.076 \\
\hline 0.015 & 0.022 & 0.008 & 0.026 & 0.000 & 0.221 \\
\hline 0.038 & 0.058 & 0.031 & 0.014 & 0.024 & 0.227 \\
\hline 0.027 & 0.056 & 0.027 & 0.029 & 0.030 & 0.235 \\
\hline
\end{tabular}

Then, $\Delta(\max )=0.235, \quad \Delta(\min )=0, \quad \Delta \mathrm{v}=0.040, \quad \varepsilon=\Delta \mathrm{v}$ $/ \Delta \max =0.170$. It is known from Eq.8, Eq.9, if $\Delta \max >3 \Delta v$, then $0.170 \leq \rho \leq 0.255$, take the median, then $\rho=0.21$.

The equation and calculation results of the correlation coefficient show as follows:

$$
\xi_{j}(\mathrm{k})=\frac{\Delta(\min )+\rho \times \Delta(\max )}{\Delta_{j}(\mathrm{k})+\rho \times \Delta(\max )}
$$

TABLE XIII. GREY RELATIONAL COEFFICIENT OF EACH INDEX.

\begin{tabular}{|c|c|c|c|c|c|}
\hline$\xi_{\mathbf{1}}(\mathbf{k})$ & $\xi_{\mathbf{2}}(\mathbf{k})$ & $\boldsymbol{\xi}_{3}(\mathbf{k})$ & $\boldsymbol{\xi}_{4}(\mathbf{k})$ & $\boldsymbol{\xi}_{\mathbf{5}}(\mathbf{k})$ & $\boldsymbol{\xi}_{\mathbf{6}}(\mathbf{k})$ \\
\hline 1.000 & 1.000 & 1.000 & 1.000 & 1.000 & 1.000 \\
\hline 0.928 & 0.891 & 0.975 & 0.916 & 0.724 & 0.394 \\
\hline 0.763 & 0.694 & 0.857 & 0.655 & 0.999 & 0.183 \\
\hline 0.562 & 0.461 & 0.611 & 0.778 & 0.675 & 0.179 \\
\hline 0.648 & 0.469 & 0.647 & 0.630 & 0.619 & 0.173 \\
\hline
\end{tabular}

The correlation of each index with the method of grey relational analysis only is:

TABLE XIV. GREY COEFFICIENT DEGREE RESULTS VIA GRA ONLY.

\begin{tabular}{|c|c|c|c|c|c|}
\hline $\mathbf{X}_{\mathbf{1}}$ & $\mathbf{X}_{\mathbf{2}}$ & $\mathbf{X}_{\mathbf{3}}$ & $\mathbf{X}_{\mathbf{4}}$ & $\mathbf{X}_{\mathbf{5}}$ & $\mathbf{X}_{\mathbf{6}}$ \\
\hline 0.780 & 0.703 & 0.818 & 0.796 & 0.804 & 0.386 \\
\hline
\end{tabular}

Obtain the grey correlation degree via the G1-GRA method.

TABLE XV. GREY COEFFICIENT DEGREE RESULT VIA G1-GRA.

\begin{tabular}{|c|c|c|c|c|c|}
\hline $\mathbf{X}_{\mathbf{1}}$ & $\mathbf{X}_{\mathbf{2}}$ & $\mathbf{X}_{\mathbf{3}}$ & $\mathbf{X}_{\mathbf{4}}$ & $\mathbf{X}_{\mathbf{5}}$ & $\mathbf{X}_{\mathbf{6}}$ \\
\hline 0.647 & 0.769 & 0.814 & 0.393 & 0.476 & 0.159 \\
\hline
\end{tabular}

From the table, it can be seen that when implementing loss reduction scheme for region $\mathrm{B}$, priority should be given to $\mathrm{X} 1$, $\mathrm{X} 2$ and $\mathrm{X} 3$. Taking measures to reduce the length of feeder, improve the average rate of distribution transformer and reduce the average load rate of the feeder. Thus realizing the purpose of power loss reduction and the network management optimization.

\section{CONCLUSION}

In this pater, the G1-GRA combination model is adopted to put forward a comprehensive loss evaluation scheme for regional distribution network. Through analyzing the statistic data of four region in a certain area, the optimal region to implement the loss reduction scheme is found out. What's more, this method figure out the first-rank indices from the selected six ones via G1-GRA. The combination evaluation model proved to be simple and operable. Moreover, the evaluation model avoids the problem of inconsistency of judgment matrix when using the AHP method. It helps the 
power supply enterprise master the operation efficiency of the distribution network and provide guidance for reformation and schematization of distribution network.

\section{ACKNOWLEDGEMENTS}

The authors would like to thank the project sponsor. The project is supported by science and technology projects Fund of Yangquan Power Supply Company of China. (No. SGSXYQOOXTJS (2014)263)

\section{REFERENCES}

[1] Zhang Yongjun, Shi Hui. Distribution network energy-saving investment compact planning based on grey connectedness weighting [J]. Automation of Electric Power Systems, 2010, 34(22):46-50.

[2] Yang Xiaobin, Li Heming. Finite set optimal predictive control for neutral point clamped three-level grid-connected inverter $[\mathrm{J}]$. Automation of electric power systems, 2013, 37(21): 146-150.

[3] Qiu Zejing, Xiang Tieyuan, Chen Hongkun, Yin Jie. Evaluation of Distribution Network Loss Reduction Potential Based on Improved Gray Relation [J]. China Rural Water and Hydropower, 2013: 106: 108.

[4] Huang Yuansheng, Song He, Tang Xinfa, Tian Lixia, Wan Youwei. Research on $\mathrm{G}_{1}$-GRA based comprehensive performance evaluation model for thermal power plant [J]. Journal of North China Electric Power University, 2014, 41 (2):99-102.

[5] Chen Shu, Yu Di, Wu Liming. Fatigue risk fuzzy evaluation for high-risk operations based on $\mathrm{G}_{1}$ method [J]. Journal of Safety Science and Technology, 2014, 10(4)90-95.

[6] Guo Yajun. Comprehensive evaluation theory and method [M]. Beijing: Science Press, 2002.

[7] Wang Xuejun, Guo Yajun. Based on the $\mathrm{G}_{1}$ method of the consistency of the judgment matrix analysis [J]. Chinese Management Science, 2006, 6(3):65-70.

[8] Liu, S.F, et al. Gray System Theory and its Application [M].Beijing: China Science Press, 2000.

[9] Zhang Daotian, Yan Zheng, Han Dong, Zhang Nana, Chen Hui, Yu Nanhua. A Grey Clustering Based Evaluation on Technical Advancement of Smart Substation [J]. Power System Technology, 2014, 38(7): 1724-1730. 